\title{
Case Report \\ Kawasaki Shock Syndrome in a 12-Year-Old Girl Mimicking Septic Shock
}

\author{
Vindika Prasad Sinhabahu, ${ }^{1}$ Janani Suntharesan, ${ }^{2}$ and Dimuthu Saraji Wijesekara ${ }^{1}$ \\ ${ }^{1}$ Professorial Paediatric Unit, Colombo South Teaching Hospital, Kalubowila, Sri Lanka \\ ${ }^{2}$ Professorial Paediatric Unit, Lady Ridgeway Hospital for Children, Colombo, Sri Lanka \\ Correspondence should be addressed to Vindika Prasad Sinhabahu; sinbad.lk@gmail.com
}

Received 1 September 2016; Revised 21 November 2016; Accepted 1 December 2016

Academic Editor: Lawrence Yamuah

Copyright (c) 2016 Vindika Prasad Sinhabahu et al. This is an open access article distributed under the Creative Commons Attribution License, which permits unrestricted use, distribution, and reproduction in any medium, provided the original work is properly cited.

\begin{abstract}
Kawasaki disease is diagnosed when fever lasts for more than 5 days with the presence of four out of five of the following clinical features: bilateral conjunctival congestion, changes in the lips and oral cavity, polymorphous exanthem, changes in peripheral extremities, and acute nonpurulent cervical lymphadenopathy (Nakamura et al., 2012). The average age of onset is 2 years and $90 \%$ of patients are below 5 years of age. Boys are more affected than girls (Cox and Sallis, 2009). This case report describes an adolescent female who was initially managed as having septic shock and subsequently found to have Kawasaki shock syndrome.
\end{abstract}

\section{Case Report}

A 12-year-old girl presented with high spiking fever $\left(103^{\circ} \mathrm{F}\right)$ for 3 days with headache, body aches, and an itchy rash for one day. There was no bleeding from gums, skin, urine, or stools. She did not have any urinary or respiratory symptoms. There was no contact history of fever or rash. She had a past history of simple febrile convulsions. She did not give a history of any known allergies, atopy, or asthma.

Examination revealed a febrile ill child with cervical lymphadenopathy and urticarial rash over the body which changed in the distribution with fever spikes (Figure 1). Her peripheries were warm and pulse rate was $92 / \mathrm{min}$. Blood pressure was 100/70 $\mathrm{mmHg}$. Respiratory, neurological, and abdominal examinations were normal. There was no clinical evidence of central nervous system infections.

Investigations on admission showed white blood cell (WBC) count of $5580 / \mathrm{mm}^{3}$ with $85 \%$ neutrophils and platelet (Plt) count of $116000 / \mathrm{mm}^{3}$, C-Reactive Protein (CRP) of $161 \mathrm{mg} / \mathrm{l}$, and Erythrocyte Sedimentation Rate (ESR) of $40 \mathrm{~mm} / 1$ st hour. Summary of investigations is shown in Table 1. Child was initially managed as having viral fever with the possibility of Dengue fever. She was treated with IV cefotaxime as for sepsis when high spiking fever continued with high CRP.
On Day 4 of illness, child developed nonpurulent conjunctivitis with periorbital oedema. She was noted to have haemodynamic instability with hypotension and tachycardia. She received ICU care and needed two inotropes to maintain her haemodynamic stability for 3 days (Day 4-Day 6). As the inotropes were given for short duration, significant side effects were absent. Her urine output was normal throughout the illness. With the presence of fever, rash,and haemodynamic instability, viral myocarditis, toxic shock syndrome, and Steven Johnson syndrome were considered as possible diagnosis compared to atypical Kawasaki disease (KD) with the evolving clinical situation on Day 4 of illness.

2D Echo on Day 8 of illness showed anteroseptal hypokinesia with dilated left anterior descending (LAD) artery with normal Left ventricular and right ventricular function and no pericardial effusion with a negative troponin I and CK-MB. LAD diameter was $2.3 \mathrm{~mm}$ with dilated area with a diameter of $3.5 \mathrm{~mm}$. Alanine transaminase (ALT) and aspartate transaminase (AST) were $86 \mathrm{U} / 1$ and $115 \mathrm{U} / 1$ on Day 4 which persisted above the reference range till Day 16 of illness. Serum bilirubin was $12 \mathrm{mg} / \mathrm{dl}$ on Day 4 . Ultrasound scan showed bilateral pleural effusions and moderate ascites without hepatosplenomegaly. Repeated blood cultures did not reveal any bacterial growth. Serology for measles, leptospirosis, rubella, Dengue, Epstein-Barr virus, 
TABLE 1: Summary of investigations.

\begin{tabular}{|c|c|c|c|c|c|c|c|c|c|}
\hline Day of illness & Day 3 & Day 4 & Day 5 & Day 6 & Day 7 & Day 8 & Day 10 & Day 13 & Day 20 \\
\hline $\mathrm{WBC}\left(\mathrm{mm}^{3}\right)$ & 9640 & 5580 & 6120 & 4500 & 12790 & 13830 & 20150 & 18800 & 18910 \\
\hline $\mathrm{N}(\%)$ & 78 & 85 & 83 & 89.7 & 91 & 85 & 85.2 & 79.8 & 56.5 \\
\hline $\mathrm{L}(\%)$ & 20 & 11 & 8.6 & 7.3 & 5.6 & 8.6 & 10 & 11 & 36.5 \\
\hline Plt $\left(10^{3} / \mathrm{mm}^{3}\right)$ & 178 & 116 & 110 & 105 & 133 & 130 & 245 & 385 & 709 \\
\hline $\operatorname{AST}(\mathrm{U} / \mathrm{l})$ & & 78.5 & & 115 & 123 & 81 & 64 & 128 & \\
\hline $\operatorname{ALT}(\mathrm{U} / \mathrm{l})$ & & 62.1 & & 86.3 & 85.4 & 71 & 48 & 68.7 & \\
\hline CRP (mg/l) & 107 & 161 & 289 & 251 & & & 122 & & 9.3 \\
\hline Albumin (g/l) & & & & & 23.8 & 23.5 & 23.4 & & \\
\hline Sodium $(\mathrm{mmol} / \mathrm{l})$ & & & & & 139 & 138 & 138 & & \\
\hline
\end{tabular}

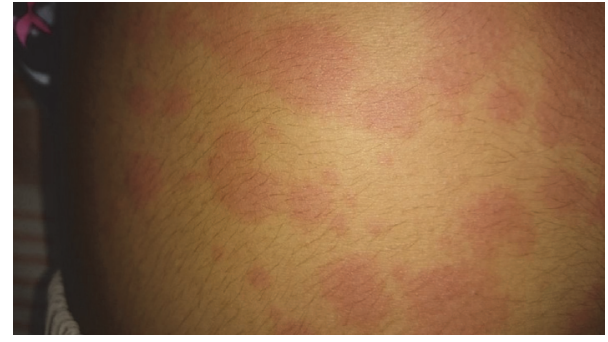

FIGURE 1: Erythematous itchy rash.

and Polymerase Chain Reaction (PCR) for influenza was negative. ANA was negative. Hypoalbuminemia was noted from Day 4 of illness and persisted for two weeks. CRP was $289 \mathrm{mg} / \mathrm{l}$ on Day 5 of illness which came down to $9.2 \mathrm{mg} / \mathrm{l}$ on Day 16. Serum Ferritin was $694.5 \mathrm{ng} / \mathrm{ml}$ on Day 10 of illness. Intravenous immunoglobulin $2 \mathrm{~g} / \mathrm{kg}$ over 24 hours was given on Day 8 of illness for the treatment of Kawasaki disease. Aspirin $80 \mathrm{mg} / \mathrm{kg}$ in four divided doses was started and continued. Fever settled on Day 10. Ascites and pleural effusions settled subsequently. Two months after the illness, child was asymptomatic and 2D Echo done two months later showed dilated LAD without aneurysm formation.

\section{Discussion}

Initial differential diagnoses in our patient are viral exanthema with myocarditis, systemic lupus erythematosus, toxic shock syndrome, Scarlet fever, systemic onset Juvenile Idiopathic Arthritis (s-JIA), Steven Johnson syndrome, and atypical KD.

$\mathrm{KD}$ is an acute febrile illness diagnosed with fever for $>5$ days with 4 out of 5 of the following signs: bilateral conjunctival congestion, changes in the lips and oral cavity, polymorphous exanthema, changes in peripheral extremities, acute nonpurulent conjunctivitis, and cervical lymphadenopathy [1]. KD is the commonest cause of acquired heart disease in children in USA [2]. Poor prognostic factors include male sex, age $<1$ year and $>8$ years, and fever lasting for $>16$ days.

Our patient had conjunctivitis, exanthema, and cervical lymphadenopathy which led to the diagnosis of atypical KD.
Serious cardiac complications in KD include coronary artery aneurysms, decreased myocardial contractility, congestive heart failure (CHF), arrhythmias, and myocardial ischemia [2]. Heart failure is reported in the febrile phase of KD [1]. The most important laboratory findings in $\mathrm{KD}$ were leukocytosis, thrombocytosis, elevated CRP and ESR, hypoalbuminemia, hyperbilirubinaemia, elevated ALT and AST, and sterile pyuria $[3,4]$. Urticarial exanthema and CRP $>10 \mathrm{mg} / \mathrm{dl}$ were identified for risk factors for coronary aneurysms which were present in our patient [4].

Toxic shock syndrome will have similar presentation with hypotension and elevated ALT and conjunctivitis but coronary artery dilation is unlikely in it [5]. Pleural effusions can occur due to concurrent infections like Mycoplasma and Streptococcus $[6,7]$. Increased microvascular permeability is seen in vasculitis of $\mathrm{KD}$ which may account for periorbital oedema [8].

Kawasaki shock syndrome (KSS) characterized by systolic hypotension or clinical signs of poor perfusion is found in $6 \%$ of $\mathrm{KD}$ patients [9]. It was a retrospective diagnosis in our patient.

One study showed serum ferritin levels were significantly elevated in s-JIA patients compared with KD patients with a cut-off value of $369.6 \mathrm{ng} / \mathrm{ml}$ [10]. It was not helpful in differentiation in our patient.

\section{Consent}

Written informed consent was obtained from the patients for publication of this case report and accompanying images.

\section{Competing Interests}

The authors declare that there is no conflict of interests regarding the publication of this paper.

\section{References}

[1] Y. Nakamura, M. Yashiro, R. Uehara et al., "Epidemiologic features of Kawasaki disease in Japan: results of the 2009-2010 nationwide survey," Journal of Epidemiology, vol. 22, no. 3, pp. 216-221, 2012. 
[2] J. R. Cox and R. E. Sallis, "Recognition of Kawasaki disease," The Permanente Journal, vol. 13, pp. 57-61, 2009.

[3] Y. Z. Sato, D. P. Molkara, L. B. Daniels et al., "Cardiovascular biomarkers in acute Kawasaki disease," International Journal of Cardiology, vol. 164, no. 1, pp. 58-63, 2013.

[4] F. J. Caballero-Mora, B. Alonso-Martín, A. Tamariz-MartelMoreno, J. Cano-Fernández, and M. Sánchez-Bayle, "Kawasaki disease in 76 patients. Risk factors for coronary artery aneurysms," Anales de Pediatría, vol. 74, no. 4, pp. 232-238, 2011.

[5] M. H. Tanner, B. J. Pierce, and D. C. Hale, "Toxic shock syndrome," Western Journal of Medicine, vol. 134, no. 6, pp. 477484, 1981.

[6] M. N. Lee, J. H. Cha, H. M. Ahn et al., "Mycoplasma pneumoniae infection in patients with Kawasaki disease," Korean Journal of Pediatrics, vol. 54, no. 3, pp. 123-127, 2011.

[7] A. Alhammadi and M. Hendaus, "Comorbidity of Kawasaki disease and group A streptococcal pleural effusion in a healthy child: a case report," International Journal of General Medicine, vol. 2013, no. 6, pp. 613-616, 2013.

[8] M. Terai, T. Honda, K. Yasukawa, K. Higashi, H. Hamada, and Y. Kohno, "Prognostic impact of vascular leakage in acute Kawasaki disease," Circulation, vol. 108, no. 3, pp. 325-330, 2003.

[9] A. Taddio, E. D. Rossi, L. Monasta et al., "Describing Kawasaki shock syndrome: results from a retrospective study and literature review," Clinical Rheumatology, 2016.

[10] M. Mizuta, M. Shimizu, N. Inoue et al., "Serum ferritin levels as a useful diagnostic marker for the distinction of systemic juvenile idiopathic arthritis and Kawasaki disease," Modern Rheumatology, vol. 26, no. 6, pp. 929-932, 2016. 


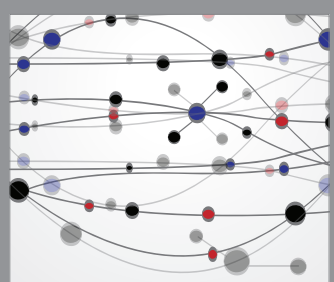

The Scientific World Journal
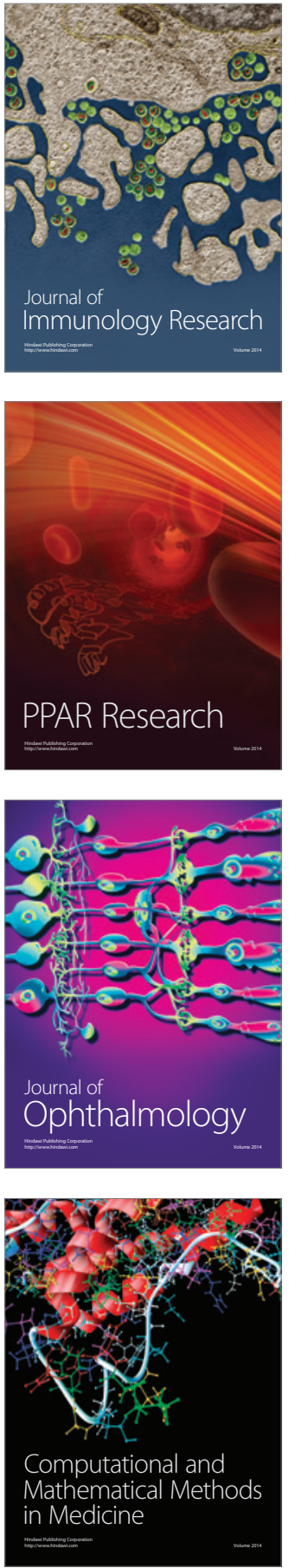

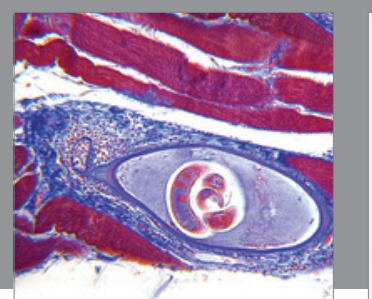

Gastroenterology Research and Practice

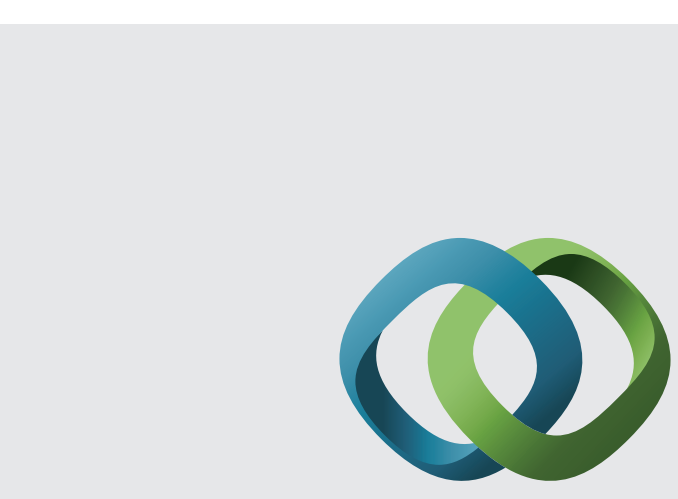

\section{Hindawi}

Submit your manuscripts at

http://www.hindawi.com
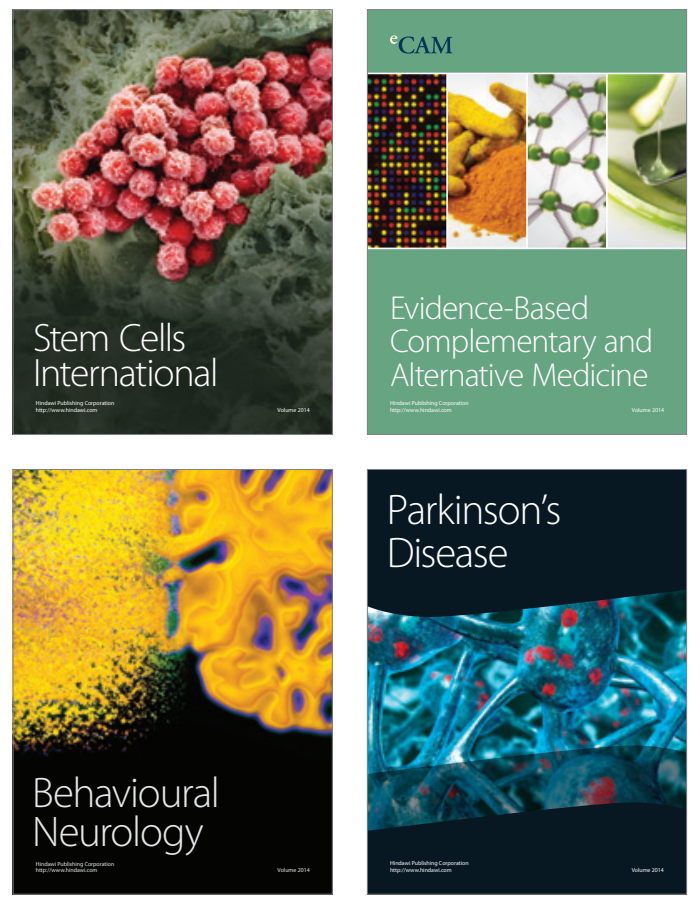
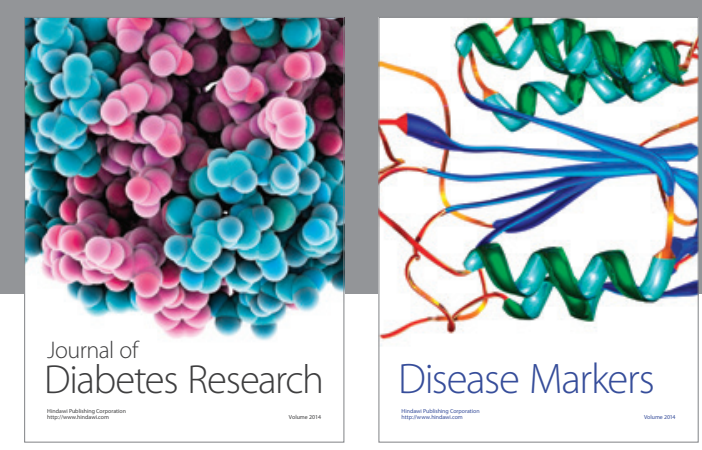

Disease Markers
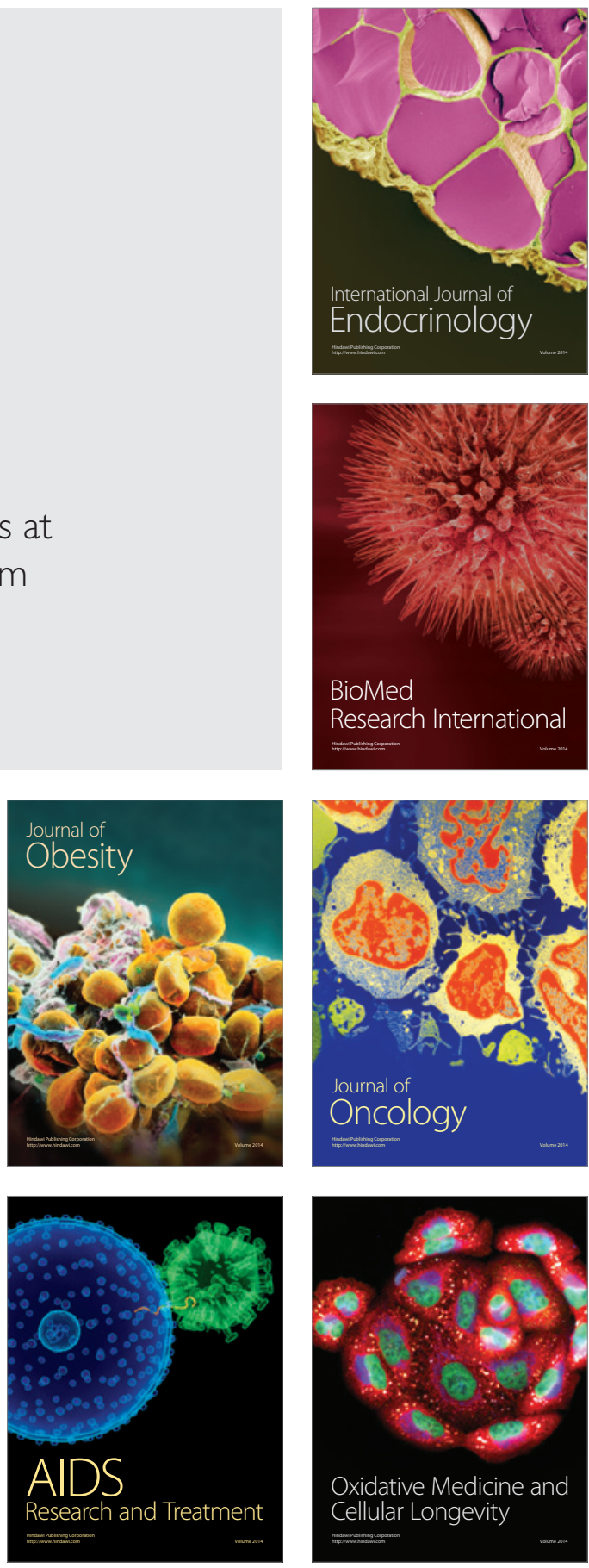